\title{
Light-induced changes in the prey consumption and behavior of two juvenile planktivorous fish
}

\author{
Clifford H. Ryer*, Bori L. Olla \\ Fisheries Behavioral Ecology Group, Alaska Fisheries Science Center, National Marine Fisheries Service, \\ NOAA, Hatfield Marine Science Center, Newport, Oregon 97365, USA
}

\begin{abstract}
Walleye pollock and sablefish, as $0+$ yr juveniles, are pelagic particulate feeding planktivores. We conducted a series of laboratory experiments to determine how illumination influences prey consumption in these species, utilizing live Artemia sp. as prey. Both juvenile walleye pollock and sablefish were characterized by a sigmoidal relationship between the log of illumination and the number of prey consumed, with greater prey consumption at higher illuminations. The threshold illumination below which fish were no longer able to visually forage was approximately $5 \times 10^{-7} \mathrm{\mu E} \mathrm{s}^{-1} \mathrm{~m}^{-2}$ for walleye pollock and $5 \times 10^{-5} \mu \mathrm{E} \mathrm{s}^{-1} \mathrm{~m}^{-2}$ for sablefish, indicating that walleye pollock are better adapted for visual feeding at depth or at night than are sablefish. This is consistent with what is known about their vertical distributions at this life stage; walleye pollock make daily vertical migrations which keep them at lower illuminations than sablefish, which remain at or near the water surface throughout the diel cycle. Although feeding more effectively in the light, both species were capable of detecting and capturing prey in darkness.
\end{abstract}

KEY WORDS: Visual threshold · Nonvisual feeding behavior $\cdot$ Illumination $\cdot$ Nocturnal

\section{INTRODUCTION}

Many planktivorous fish are visual foragers, highly dependent upon light to efficiently detect and consume their zooplankton prey. Therefore, understanding the role of light in determining where and when these fish feed is a necessary underpinning to modeling their energetics, growth and survival. The quantity and quality of light available in aquatic environments is determined, first of all, by astronomical and meteorological conditions. At the water surface, illumination may span 9 orders of magnitude, from full daylight with clear skies to moonless nights under dark storm cloud conditions (U.S. Department of the Navy 1952). Secondly, light will be further reduced by unfavorable sea surface conditions, turbidity and many other water quality variables which may vary with depth and affect spectral attenuation (McFarland 1986). Thus, the optical environment in which these fish live and forage

•E-mail: cliff.ryer@hmsc.orst.edu may vary dramatically on an hourly, daily, monthly and seasonal basis. Although some fishes avoid bright light (e.g. Olla \& Davis 1990, Sogard \& Olla 1993), the ability to visually detect prey is probably more often limited by conditions of low illumination. As a result, a number of studies have examined the illumination thresholds for feeding in various fishes, with the goal of predicting the conditions under which they will be able to forage (Blaxter 1965, Hunter 1968, Bagarinao \& Hunter 1983, Dabrowski \& Jewson 1984, Bergman 1988, Connaughton et al. 1994, Huse 1994, McMahon \& Holanov 1995). For example, Hunter (1968) found that jack mackerel Trachurus symmetricus feed effectively on Artemia sp. down to $6 \times 10^{-5} \mathrm{ft}-\mathrm{L}$ (approximately $1 \times 10^{-5} \mu \mathrm{E} \mathrm{s}^{-1} \mathrm{~m}^{-2}$ ), suggesting that they may be capable of feeding in surface waters at night when there is moonlight.

The light requirements for feeding by visual planktivores may also provide insights into other aspects of fish ecology. For example, larval and juvenile fish often undergo daily vertical migrations, with the most com- 
mon pattern involving upward movement to surface waters at or near dusk, followed by a return to the depths at dawn (Neilson \& Perry 1990). Whatever the causes and proximal mechanism involved in vertical migration, it unquestionably influences the visual environment in which fish must forage, and, conversely, it is probable that visual capabilities may partially dictate the range of vertical movements undertaken

In this study, we examine the role of light in the foraging of 2 pelagic planktivorous fishes: juvenile walleye pollock Theragra chalcogramma and juvenile sablefish Anaplopoma fimbria. Both species are inhabitants of the coastal waters of the north Pacific and form the basis of important commercial fisheries. As juveniles, walleye pollock often migrate vertically, ascending at dusk and descending at dawn (Bailey 1989). It is unknown whether this migration is a response to predation pressure, feeding opportunities, energetic considerations, or a combination of these factors, but it clearly narrows the range of light intensities experienced on a daily basis, compared, that is, to a fish that exclusively occupies surface waters. Juvenile walleye pollock have relatively large eyes and have generally been assumed to be visual foragers (Olla \& Davis 1990). Juvenile walleye pollock decrease activity at night (Sogard \& Olla 1996, Ryer \& Olla 1998) and cease schooling (Brodeur \& Wilson 1996, Ryer \& Olla 1998). These observations suggest that the walleye pollock is a visually oriented diurnal species, which has been reinforced by behavioral studies demonstrating that they visually monitor foraging conspecifics for cues that may reveal the location of prey patches (Baird et al. 1991, Ryer \& Olla 1995, 1997). This does not preclude, however, their being capable of feeding under conditions of low light by using sensory modalities other than vision (e.g. Merati \& Brodeur 1996).

Juvenile sablefish also school, but are more active than walleye pollock (Ryer \& Olla 1997). Like the walleye pollock, they also feed upon zooplankton, but available data suggest that they do not make extensive daily vertical migrations, remaining, instead, near the surface both day and night (Shenker \& Olla 1986, Sogard \& Olla 1998). In addition, these data indicate that juvenile sablefish are diurnal feeders, suggesting that they may not be capable of detecting prey at low illuminations (Sogard unpubl.).

We exposed both species to surrogate planktonic prey, live Artemia sp., under varying illumination, determining the number of prey consumed and observing foraging behavior. On the basis of what was known about their vertical distributions and feeding behavior, we hypothesized that juvenile walleye pollock would have a lower light threshold than juvenile sablefish for visually mediated foraging.

\section{MATERIALS AND METHODS}

Fish collection and maintenance. During June 1996 juvenile walleye pollock were collected at night from Puget Sound, Port Townsend, WA, USA, by dipnetting them as they aggregated around a light. Juvenile sablefish Anaplopoma fimbria were captured during April 1996 using a neuston net at night, approximately $32 \mathrm{~km}$ off Newport, OR, USA. At the time of collection, juveniles ranged from 20 to $50 \mathrm{~mm}$ TL (total length). Fish were transported back to our laboratory in Newport and maintained in $3000 \mathrm{l}$ circular tanks provided with a continuous flow of seawater: salinity range 28 to $33 \%$, temperature range 9 to $13^{\circ} \mathrm{C}$. Both species were fed pelletized food daily, and, while the exact ration was not measured, it was sufficient to promote growth. Fish were held for 2 to 4 wk prior to experimentation. Although they received no live food during this period, preliminary experiments revealed that both walleye pollock and sablefish would readily attack live prey if given the opportunity.

Infrared observation tanks. Experiments were conducted using 4 identical glass tanks $(50 \times 50 \times 50 \mathrm{~cm}$, $\mathrm{W} \times \mathrm{L} \times \mathrm{H}$ ) supported by a plexiglass platform and surrounded by a light-proof blind in a dark room. A single inflow pipe, which extended vertically to within $1 \mathrm{~cm}$ of the tank bottom, supplied seawater to each tank. while 2 drain holes allowed for outflow. For each tank, a feeding tube passed through a sleeve in the blind, allowing the tube to be lowered to the water's surface to introduce prey and then withdrawn with minimal disturbance. Each tank was illuminated from below with a $60 \mathrm{~W}$ LED infrared (IR) illuminator. The wavelength of emitted IR light peaked at $880 \mathrm{~nm}$, with no emissions below $760 \mathrm{~nm}$. Fish are insensitive to light in this range (Douglas \& Hawryshyn 1990) and IR illumination has been utilized by other researchers to examine fish behavior under low visible light conditions (John 1964, Pitcher \& Turner 1986, Higgs \& Fuiman 1996). A sheet of light diffusing material, commonly utilized in overhead fluorescent fixtures, was positioned between the tanks and the plexiglass platform, and, when illuminated from below, produced a diffuse bright background against which fish could be viewed as silhouettes from above. A video camera, with spectral sensitivity well into the IR range, was positioned above each tank and cabled to a video recorder and monitor in another room. Four green LED illuminators were positioned above each tank to provide visible illumination. These illuminators emitted within a narrow spectral range of approximately $10 \mathrm{~nm}$, with a peak at $555 \mathrm{~nm}$, and were digitally controlled using a micro-computer, allowing incremental manipulation of illumination from $1.90 \times 10^{-7}$ to $1.55 \times 10^{-3} \mathrm{\mu E} \mathrm{s}^{-1} \mathrm{~m}^{-2}$, measured at the water surface. Higher light levels 
$\left(1.50 \times 10^{-2}\right.$ and $\left.1.50 \times 10^{-1} \mu \mathrm{E} \mathrm{s}^{-1} \mathrm{~m}^{-2}\right)$ were achieved by augmenting the green LED output with the additional light emitted by a rheostat controlled $15 \mathrm{~W}$ incandescent bulb positioned above each tank.

Light measurements. Measurements in each replicate tank were made at the beginning of the study, but occasional measurements at later dates confirmed that lighting was consistent throughout the study. Measurements were made with an IL1700 Research Radiometer manufactured by International Light, Newburyport, MA, USA, equipped with a PAR (photosynthetically active radiation) filtered, cosine response, underwater detector, sensitive to $1 \times 10^{-8} \mu \mathrm{E} \mathrm{s}^{-1} \mathrm{~m}^{-2}$. Measurements were made with IR illuminators turned off. We recorded light intensity at the waters surface, for each preselected light intensity, with the detector pointing straight upwards. Illumination in the 4 replicate tanks did not differ by more than $13 \%$, for any preselected light level, and values reported in this paper represent the mean of these 4 measurements. To characterize the angular distribution of light in the observation tanks, we made more complete measurements at a single illumination level $\left(1.55 \times 10^{-3} \mu \mathrm{E} \mathrm{s}^{-1} \mathrm{~m}^{-2}\right)$ in each replicate tank, assuming that this light distribution remained comparable across the entire range of illuminations examined in our experiments. We measured illumination in the center of the tank at the waters surface, mid-water and bottom, with the detector pointed straight upwards. At mid-water, we also measured light intensity with the detector pointed towards each of the 4 walls of each tank (laterally), and pointed downwards. Downwelling illumination did not decrease appreciably with depth in the tanks, with surface and bottom measurements differing by only an average of $6 \%$ (SD $=11.2$ ). At middepth, light emanating from the sides of the tank was, on average, $15 \%(\mathrm{SD}=5.7)$ of that downwelling from the surface. Due to reflection from the glass bottoms of the tanks, light upwelling from below averaged $36 \%$ ( $S D=8.6$ ) of that downwelling from above.

General experimental protocol. Experiments followed the same general protocol, with groups of 5 fish haphazardly selected from holding tanks and introduced to the IR tanks at approximately 16:00 h the day before experimentation. Lights were turned off for the night at 19:00 h, then turned on again at 07:00 $\mathrm{h}$ the next day. Three hours later, the inflow water to each IR tank was turned off and the water level in the tank siphoned down to approximately $2 \mathrm{~cm}$ below the outflow tubes. This lowered the water depth from 43 to $39 \mathrm{~cm}$, reducing water volume from 106 to $93 \mathrm{l}$, and assured that prey would not be lost in the outflow water. This process typically took a total of $5 \mathrm{~min}$. Next, visible illumination was adjusted to the intended experimental level and the IR illuminators were turned on. Fish were allowed to acclimate for $60 \mathrm{~min}$, after which they were videotaped during a 30 min pre-feeding period, followed by prey introduction and videotaping of feeding behavior. Live adult Artemia sp., obtained weekly from a pet store, were used as prey. Prey were not fed during the study. Two hundred prey were counted and placed into a $100 \mathrm{ml}$ beaker of seawater 30 min prior to being introduced to the IR tank. Prey introduction entailed lowering the feeding tube, slowly pouring the $100 \mathrm{ml}$ of seawater containing the prey into the feeding tube, followed by rinsing down the beaker and the feeding tube with more seawater, assuring that no prey remained in the beaker or feeding tube. The feeding tube was then withdrawn. These 200 prey correspond to a prey density of approximately 2 prey $\mathrm{l}^{-1}$. Observations indicated that prey dispersed throughout the IR tanks within $1 \mathrm{~min}$. The duration of the feeding period varied between experiments. At the end of the feeding period, the IR illumination was turned off and both fish and prey were quickly dipnetted from the IR tank and immediately separated. The remaining prey were enumerated and the fish weighed and measured. Used fish were then placed into a holding tank and were not utilized again for subsequent trials.

Walleye pollock threshold experiment. We recorded prey consumption in total darkness $\left(<1.0 \times 10^{-8} \mu \mathrm{E} \mathrm{s}^{-1}\right.$ $\mathrm{m}^{-2}$ ambient light), dark $\left(<1.0 \times 10^{-8} \mathrm{\mu E} \mathrm{s}^{-1} \mathrm{~m}^{-2}\right.$ ambient plus supplemental IR), and under visible light intensities of $1.90 \times 10^{-7}, 1.05 \times 10^{-6}, 1.58 \times 10^{-5}, 1.65 \times 10^{-4}$, $1.55 \times 10^{-3}$ and $1.50 \times 10^{-2} \mu \mathrm{E} \mathrm{s}^{-1} \mathrm{~m}^{-2}$ (not counting IR illumination). Four replicate trials were conducted at each illumination, with fish given $10 \mathrm{~min}$ to feed. The order of light treatment trials was randomized, with the entire experimental series completed over a span of $15 \mathrm{~d}$. Although fish ranged from 42 to $67 \mathrm{~mm} \mathrm{TL}$, mean fish size did not differ between illuminations (total darkness: $\operatorname{mean}, \bar{x}=56.1 \mathrm{~mm}, \mathrm{SE}=1.4$; dark[+IR]: 54.0, $1.2 ; 10^{-7}: 56.8,1.1 ; 10^{-6}: 56.1,0.7 ; 10^{-5}: 55.4,1.0 ; 10^{-4}$ : $55.2,1.1 ; 10^{-3}: 55.1,1.2 ; 10^{-2}: 53.4,0.9 ; F_{6,133}=1.26, \mathrm{p}=$ 0.281 ). Prey consumption data were analyzed by ANOVA (Sokal \& Rohlf 1969) and a posteriori multiple comparisons using Ryan's Q-test (Day \& Quinn 1989). Actively foraging fish swam about in the interior of the tank, whereas nonforaging fish typically swam along the walls. To quantify this difference and obtain a time series of feeding activity through the experiment, we recorded the number of fish occupying the interior area of the tank at $2 \mathrm{~min}$ intervals, from $8 \mathrm{~min}$ before prey introduction to $8 \mathrm{~min}$ afterwards. The interior of the tank was defined by a square centered on the tank bottom with sides $25 \%$ shorter than the tank bottom (56\% of the bottom area). For swim speeds, a single fish was haphazardly chosen and its swim path digitized over a $1 \mathrm{~min}$ period. This was repeated at 2 min intervals, starting $8 \mathrm{~min}$ before prey introduction and continuing 
till 8 min afterwards. Swim speeds were corrected for the average fish size in each trial. We visually examined data for each light level to determine if either of these behavioral measures showed a pattern of change through the course of either the pre-feeding or the feeding period. Given the variability of the data, there were no discernible patterns in either the pre-feeding or the feeding period data, and data were therefore averaged within the pre-feeding and feeding periods, respectively, for each light level. The resultant data were analyzed by repeated-measures ANOVA and a posteriori multiple comparisons using Ryan's Q-test.

Sablefish threshold experiment. The first of 2 preliminary experiments with juvenile sablefish compared prey consumption in total darkness $\left(<1.0 \times 10^{-8} \mu \mathrm{E} \mathrm{s}^{-1}\right.$ $\mathrm{m}^{-2}$ ambient light) with that under IR illumination $\left(<1.0 \times 10^{-8} \mu \mathrm{E} \mathrm{s}^{-1} \mathrm{~m}^{-2}\right.$ ambient plus supplemental IR illumination), with fish given 60 min to feed. Six replicate trials were conducted for each treatment, with 2 trials of each treatment conducted daily during 3 consecutive days. Fish in this experiment ranged from 59 to $80 \mathrm{~mm} \mathrm{TL}$; however, mean length did not differ between treatments $($ dark $[+\mathrm{IR}]: \bar{x}=68.5, \mathrm{SE}=0.9$ i total darkness: $67.5,0.7 ; t=-0.85, \mathrm{df}=58, \mathrm{p}=0.401$ ). No video recording or behavioral observations were made in this experiment. Consumption data were analyzed using the $t$-test (Sokal \& Rohlf 1969). The second preliminary experiment compared prey consumption in the dark (+IR) with consumption at an illumination of $1.50 \times 10^{-1} \mu \mathrm{E} \mathrm{s}^{-1} \mathrm{~m}^{-2}$. Six replicate trials were conducted for each treatment, with fish given $15 \mathrm{~min}$ to feed. Again, 2 trials of each treatment were conducted daily during 3 consecutive days. Fish in this experiment ranged from 66 to $88 \mathrm{~mm} \mathrm{TL}$, with no difference in mean length between treatments (dark [+IR]: $\bar{x}=$ 75.3, $\mathrm{SE}=0.8 ;$ light: 73.9, 0.9; $t=1.08, \mathrm{df}=58, \mathrm{p}=$ $0.285)$. All prey were consumed in each trial of the light treatment, resulting in zero variance, so a Mann-Whitney $U$-test was utilized to test for differences in consumption between light and dark trials. In this second experiment, we also made behavioral observations from videotapes. Sablefish swam along the tank walls more than walleye pollock did, although sablefish did tend to move out and across the interior of the tank more frequently when actively foraging. Rather than count the number of fish in the tank's interior, as we had done with walleye pollock, we recorded the frequency at which fish transited the interior region of the tank. Again, the tank interior was defined by a square with sides $25 \%$ shorter than the dimensions of the tank bottom. The number of times fish transited this square in a 1 min period was recorded. This was repeated every other minute, from $8 \mathrm{~min}$ before prey introduction to 12 min afterwards for both treatments. Transit data were rank transformed to achieve homogeneity of variance, then subjected to repeated-measures ANOVA (Hicks 1982) and a posteriori multiple comparisons using Ryan's Q-test (Day \& Quinn 1989). These analyses revealed that transits peaked immediately after prey introduction in the light and 8 min later in the dark. During a 1 min period, starting at each of these respective peaks $10 \mathrm{~min}$ in the light, $8 \mathrm{~min}$ in the dark), for each trial we measured the swimming speed of 5 haphazardly chosen fish as they made transits. For the pre-feeding period, swim speeds were measured for the first 5 fish to make transits, beginning $2 \mathrm{~min}$ prior to prey introduction. Swim speeds were corrected for the average fish size in each trial and then averaged by trial. Swim speeds were compared between dark and light trials using a t-test (Sokal \& Rohlf 1969) with Satterwaites adjusted degrees of freedom (Day \& Quinn 1989) to account for heteroscedasticity

Subsequent experimentation to determine the light threshold for visually mediated feeding in juvenile sablefish examined the following visible light intensities, not counting irradiance from the IR illuminators: $<1.0 \times 10^{-8}$ (dark), $1.05 \times 10^{-6}, 1.58 \times 10^{-5}, 1.65 \times 10^{-4}$. $1.55 \times 10^{-3}$ and $1.50 \times 10^{-2} \mu \mathrm{E} \mathrm{s}^{-1} \mathrm{~m}^{-1}$. Due to a limited number of fish, we conducted 2 replicate trials at each illumination, with fish given $10 \mathrm{~min}$ to feed. The order of light treatment trials was randomized, with the entire experimental series conducted during 3 consecutive days. Fish ranged from 79 to $114 \mathrm{~mm}$ TL, but mean length did not differ significantly between light treatments (dark: $\bar{x}=90.0 \mathrm{~mm}, \mathrm{SE}=2.1 ; 10^{-6}: 97.8,3.1$; $10^{-5}: 97.3,2.5 ; 10^{-4}: 99.4,2.5 ; 10^{-3}: 97.3,2.8 ; 10^{-2}: 99.8$, 3.5; $F=1.32, \mathrm{df}=5, \mathrm{p}=0.269$ ). Prey consumption was analyzed by ANOVA and a posteriori multiple comparisons using Ryan's Q-test. No behavioral observations were made. Because procedures for threshold trials differed somewhat for walleye pollock and sablefish, no direct statistical comparisons of the effect of light on prey consumption by these 2 species were made.

Walleye pollock endogenous rhythm experiment. We conducted an experiment with juvenile walleye pollock to address the potential influence of an endogenous rhythm on prey consumption in the light versus dark. These trials were conducted at 01:00 h, with 6 trials conducted in darkness and 6 trials at an illumination of $1.55 \times 10^{-3} \mu \mathrm{E} \mathrm{s}^{-1} \mathrm{~m}^{-2}$, with fish given $10 \mathrm{~min}$ to feed. Fish ranged from 53 to $74 \mathrm{~mm} \mathrm{TL}$, with a mean length of $63.5 \mathrm{~mm}$. Two trials of each light treatment were conducted each night, over 3 consecutive nights. Prey consumption was compared to that of corresponding illuminations from the threshold determination experiment conducted during the day. Because night trials were conducted approximately 1 mo after day trials, fish in night trials were significantly larger (see 'Results'). Consumption data were analyzed by ANOVA 


\section{RESULTS}

\section{Walleye pollock and sablefish visual threshold and behavior}

Juvenile walleye pollock did not make use of IR illumination in their foraging, as indicated by numbers of prey consumed not differing between IR lighting and total darkness (dark [IR]: $\bar{x}=39.5, \mathrm{SE}=8.8$; total darkness: $28.3,8.8 ; t=-0.90, \mathrm{df}=6, \mathrm{p}=0.401$ ). Examination of a range of visible illuminations revealed a sigmoidal relationship between the log of illumination and number of prey consumed by juvenile walleye pollock (Fig, 1, Table 1), with the threshold illumination at which feeding performance increased being between $10^{-7}$ and $10^{-6} \mu \mathrm{E} \mathrm{s}^{-1} \mathrm{~m}^{-2}$ (geometric $\bar{x}=5 \times 10^{-7} \mu \mathrm{E} \mathrm{s}$ $\mathrm{m}^{-2}$ ). Actively foraging fish spent more time in the tank interior, whereas fish that were not actively foraging tended to swim along the tank walls. Occupancy of the tank interior and swimming speed did not change appreciably during the course of either the pre-feeding or feeding period, and data were therefore averaged by period. Increasing light intensity stimulated fish towards greater occupancy of the tank interior, both with and without prey present (Fig. 2a, Table 2). With prey present, interior occupancy showed an apparent increase at $10^{-6} \mu \mathrm{E} \mathrm{s}^{-1} \mathrm{~m}^{-2}$, the same light level at which prey consumption increased. The swimming speed of fish in the presence of prey was also influenced by light intensity (Fig. 2b. Table 3). Juvenile walleye pollock swam slowly in the darkness, but appeared to increase their speed at an illumination of $10^{-7} \mu \mathrm{E} \mathrm{s}^{-1} \mathrm{~m}^{-2}$. There was a dip in swimming speed at $10^{-6} \mu \mathrm{E} \mathrm{s}^{-1} \mathrm{~m}^{-2}$, the same light intensity at which both prey consumption and interior use increased.

Like walleye pollock, juvenile sablefish either do not detect or are unable to effectively utilize IR light to feed, as demonstrated by comparable numbers of prey

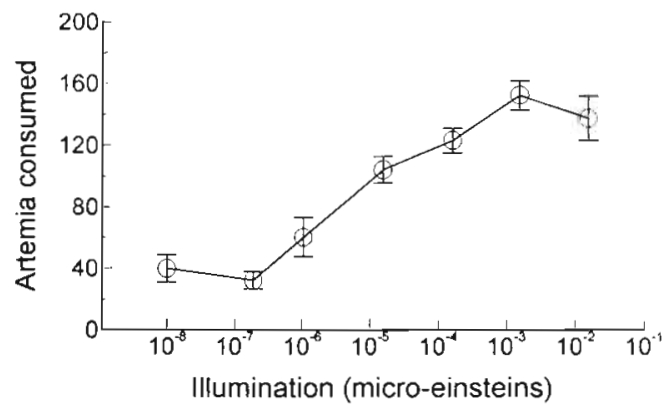

Fig. 1. Theragra chalcogramma. Mean number of prey $( \pm \mathrm{SE})$ consumed by groups of 5 juvenile walleye pollock at illuminations ranging from $10^{-8}$ (darkness) to $10^{-2} \mu \mathrm{E} \mathrm{s}^{-1} \mathrm{~m}^{-2}$ Reported light levels do not include light from the IR illuminators. Four replicate trials were conducted for each treatment, with fish allowed $10 \mathrm{~min}$ to feed consumed under IR lighting $(\bar{x}=65.7, \mathrm{SE}=9.9)$ and in total darkness $(68.5,12.4 ; t=0.18, \mathrm{df}=10, \mathrm{p}=0.862)$. For sablefish, we conducted a preliminary experiment, comparing prey consumption and behavior in the dark with that at an illumination of $1.5 \times 10^{-1} \mu \mathrm{E} \mathrm{s}^{-1} \mathrm{~m}^{-2}$. In

Table 1. Analysis of juvenile walleye pollock prey consumption under visible light intensities ranging from $10^{-8}$ (darkness) to $10^{-2} \mu \mathrm{E} \mathrm{s}^{-1} \mathrm{~m}^{-2}$. Light intensities are listed in order of ascending prey consumption. Prey consumption at underlined light intensities $\left(\mu \mathrm{E} \mathrm{s} \mathrm{s}^{-1} \mathrm{~m}^{-2}\right)$ did not differ significantly $(\mathrm{p}<0.05)$

ANOVA: $F_{6,21}=23.30, p<0.001$

\begin{tabular}{llllll}
$10^{-7} 10^{-8}$ (dark) & $10^{-6}$ & $10^{-5}$ & $10^{-4}$ & $10^{-2}$ & $10^{-3}$ \\
\hline & & & & & \\
\hline & & \\
\hline
\end{tabular}

a)
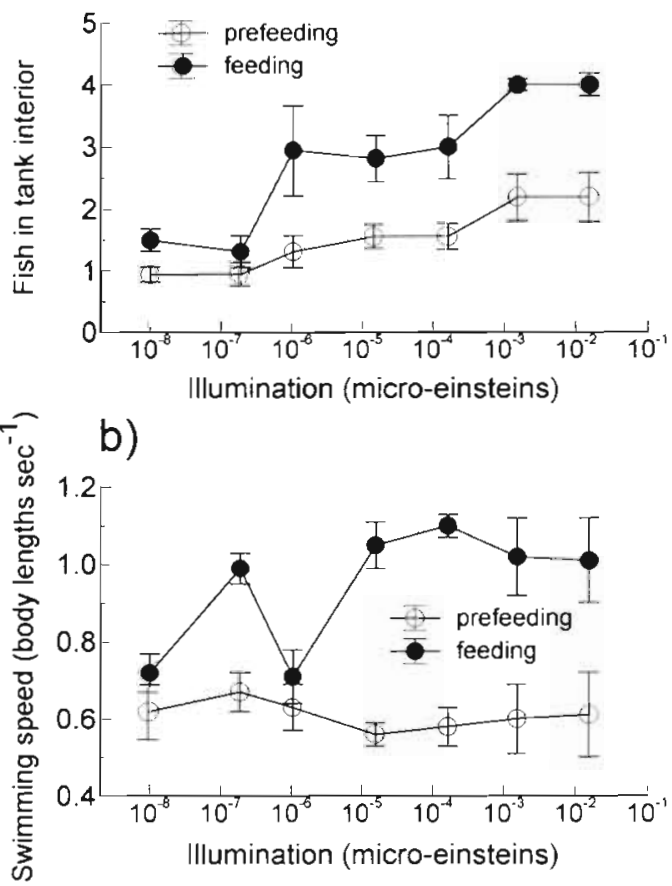

Fig. 2. Theragra chalcogramma. (a) Mean number of juvenile walleye pollock $( \pm \mathrm{SE}$ ) foraging in the tank's interior during pre-feeding and the 10 min feeding period, at illuminations ranging from $10^{-8}$ (darkness) to $10^{-2} \mu \mathrm{E} \mathrm{s}^{-1} \mathrm{~m}^{-2} \mathrm{~A}$ fish was considered to be in the interior of the tank when it was in a square, centered on the tank bottom, with sides $25 \%$ shorter than the dimensions of the tank bottom (56\% tank bottom area). Fish outside this square were commonly engaged in nonforaging behavior such as swimming against/along the glass walls of the tank. (b) Mean swimming speed of juvenile walleye pollock $( \pm \mathrm{SE})$, during pre-feeding and the $10 \mathrm{~min}$ feeding period, at illuminations ranging from $10^{-8}$ (darkness) to $10^{-2} \mu \mathrm{E} \mathrm{s}^{-1} \mathrm{~m}^{-2}$. Light levels do not include light from the IR illuminators 
subsequent trials we examined prey consumption at a wider range of illuminations to determine the visual foraging threshold, but without behavioral observations. In the preliminary experiment, prey consumption was greater in the light than in the darkness (Mann-Whitney, $\mathrm{p}=0.002$ ), with all 200 prey consumed during each of the light trials, compared to

Table 2. Analysis of the numbers of juvenile walleye pollock occupying the interior of aquaria under various light intensities during pre-feeding and feeding periods. Light intensities are listed in order of ascending number of pollock in the interior of the aquaria. Numbers of fish at underlined light intensities $\left(\mu \mathrm{E} \mathrm{s}^{-1} \mathrm{~m}^{-2}\right)$ did not differ significantly $(\mathrm{p}<0.05)$

$$
\begin{aligned}
& \text { Pre-feeding ANOVA: } F_{6.21}=3.88, p=0.009
\end{aligned}
$$

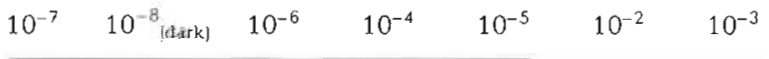$$
\text { Feeding ANOVA: } F_{6,21}=6.64, \mathrm{p}=0.001
$$

\begin{tabular}{lllllll}
$10^{-7}$ & $10^{-8}$ Idark & $10^{-5}$ & $10^{-6}$ & $10^{-4}$ & $10^{-2}$ & $10^{-3}$ \\
\hline
\end{tabular}

Table 3. Analysis of juvenile walleye pollock swimming speeds under various light intensities during pre-feeding and feeding periods. Light intensities are listed in order of ascending swimming speed. Swimming speeds at underlined light levels $\left(\mu \mathrm{E} \mathrm{s}^{-1} \mathrm{~m}^{-2}\right)$ did not differ significantly $(\mathrm{p}<0.05)$

$$
\begin{aligned}
& \text { Pre-feeding ANOVA: } F_{6.21}=0.30, \mathrm{p}=0.930 \\
& \text { Feeding ANOVA: } F_{6,21}=5.10, \mathrm{p}=0.002 \\
& 10^{-6} \quad 10^{-8} \text { (dark) } \quad 10^{-7} \quad 10^{-2} \quad 10^{-3} \quad 10^{-5} \quad 10^{-4}
\end{aligned}
$$

Table 4. Analysis of juvenile sablefish transit frequencies in the light $\left(10^{-1}\right)$ and the dark $\left(<10^{-8} \mu \mathrm{E} \mathrm{s}^{-1} \mathrm{~m}^{-2}\right)$. Times, prior to and after prey introduction, are listed in order of ascending transit frequency. Transit frequencies at underlined times (min) did not differ significantly $(p<0.05)$

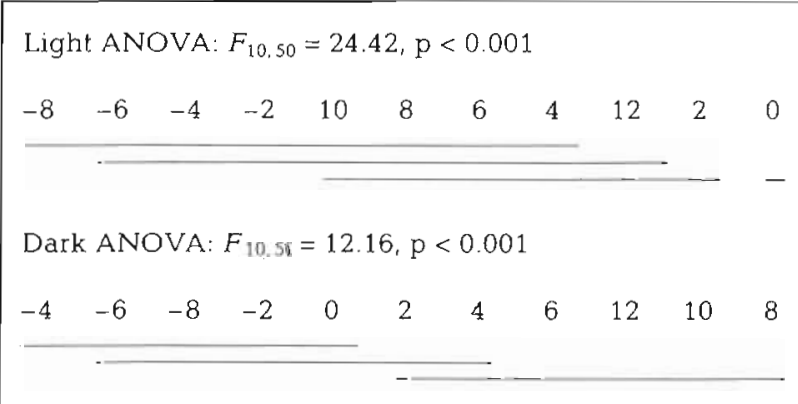

approximately one-third that number in the dark trials $(\bar{x}=67.8, \mathrm{SE}=10.5)$. Rather than counting the number of fish in the tank interior, we recorded the frequency with which fish transited the border of the tank interior, as this measure demonstrated less variability and greater responsiveness to light level. Under both dark and light conditions, fish oriented to and swam along the walls of the tank when prey were absent, but made more frequent transits of the tank interior when prey were present (Fig. 3a, Table 4). The frequency of transits also suggests that the time course of foraging differed between light and darkness. Fish in the light exhibited their peak transit frequencies immediately after prey introduction and then rapidly returned to pre-feeding levels, while in the dark transits increased more gradually and did not reach a peak until $8 \mathrm{~min}$ after prey introduction. (Fig. 3a, Table 4). Prior to prey introduction, there had been no significant difference in swimming speed between fish in the light and fish in the dark (dark: $\bar{x}=0.88$ body lengths $\mathrm{s}^{-1}, \mathrm{SE}=0.11$; light: $0.98,0.6 ; t=-0.85, \mathrm{df}=10, \mathrm{p}=0.418$ ), but, during their respective transit peaks after prey introduction, fish in the light swam significantly faster than fish in the dark (Fig. 3b, $t=-7.48$, df $_{\text {adjusted }}=5.5, p<0.001$ ).

As was the case for walleye pollock, subsequent testing of a wider range of illuminations revealed a sigmoidal relationship between the log of illumination and the number of prey consumed (Fig. 4, Table 5). The visual foraging threshold for sablefish occurred between $10^{-5}$ and $10^{-4} \mu \mathrm{E} \mathrm{s}^{-1} \mathrm{~m}^{-2}$ (geometric $\bar{x}=5 \times$ $10^{-5} \mu \mathrm{E} \mathrm{s}^{-1} \mathrm{~m}^{-2}$ ), roughly 2 orders of magnitude above the walleye pollock's threshold.

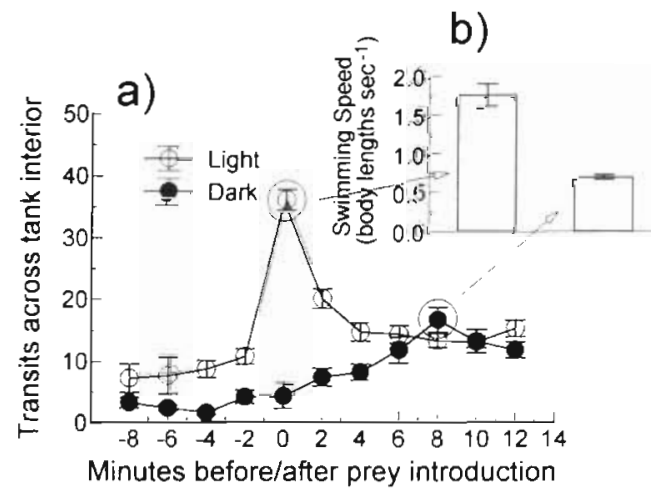

Fig. 3. Anaplopoma fimbria. (a) Mean number of transits $( \pm \mathrm{SE})$ across the interior of the tank by juvenile sablefish in darkness $\left(10^{-8}\right)$ and in the light $\left(10^{-2} \mu \mathrm{E} \mathrm{s}^{-1} \mathrm{~m}^{-2}\right.$, not including IR). A transit occurred when a fish traversed the border of a square, centered on the tank bottom, with sides $25^{\prime \prime}$. shorter than the dimensions of the tank bottom (56\% tank bottom area). Transits were counted during 1 min periods, beginning 8 min prior to prey introduction and continuing till $12 \mathrm{~min}$ afterwards. (b) Mean swimming speed $( \pm \mathrm{SE})$ of fish during peak transit periods in the light and in darkness 


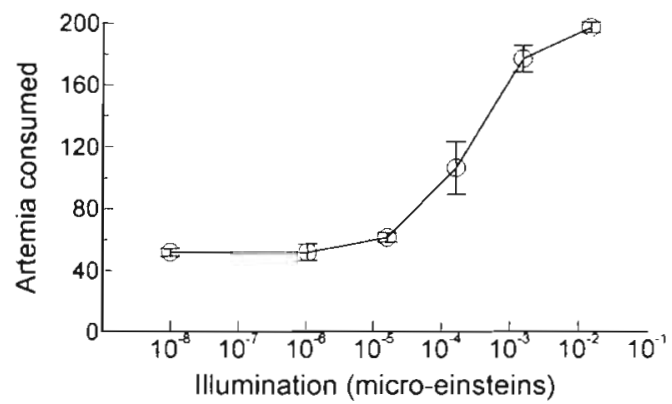

Fig. 4. Anaplopoma fimbria. Mean number of prey consumed $( \pm \mathrm{SE})$ by groups of 5 juvenile sablefish at illuminations ranging from darkness $\left(10^{-8}\right)$ to $10^{-1} \mu \mathrm{E} \mathrm{s}^{-1} \mathrm{~m}^{-2}$ Reported light levels do not include light from the IR illuminators. Two replicate trials were conducted for each treatment, with fish allowed $10 \mathrm{~min}$ to feed
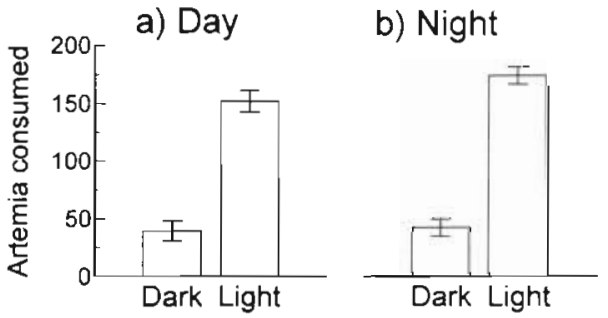

Fig. 5. Theragra chalcogramma. Mean number of prey $( \pm \mathrm{SE})$ consumed by groups of 5 juvenile walleye pollock in darkness $\left(10^{-8}\right)$ and in the light $\left(10^{-3} \mu \mathrm{E} \mathrm{s}^{-1} \mathrm{~m}^{-2}\right)$ (a) during the day and (b) during the night. Light levels do not include light from the IR illuminators. Six replicate trials were conducted for each treatment, with fish allowed to forage for $10 \mathrm{~min}$

At higher illuminations, both juvenile walleye pollock and sablefish engaged in particulate feeding, with fish moving to intercept prey from a distance, then engulfing them with a brief expansion of the oral cavity and a brief snapping of the jaws. In the dark, both species adopted a more exaggerated mode of particulate feeding, which involved greater distension of the oral cavity as well as the intake of a greater quantity of water and sometimes the prey. After a prey item was detected, a fish would orient its heads to bring its mouth near the prey. Since prey were detected only when they were very close $(\leq 1 \mathrm{~cm})$, this often involved convoluted body gyrations and sinusoidal backing behavior. Attempts to engulf prey were often repeated 2 or 3 times in slightly different directions, suggesting that fish were unable to precisely determine prey location.

\section{Walleye pollock endogenous rhythm experiment}

Time of day had no effect on the prey consumption of juvenile walleye pollock $\left(F_{1,16}=2.20, p=0.157\right)$. Fish
Table 5. Analysis of juvenile sablefish prey consumption under visible light intensities ranging from $10^{-8}$ (darkness) to $10^{-2} \mu \mathrm{E} \mathrm{s}^{-1} \mathrm{~m}^{-2}$. Light intensities are listed in order of ascending prey consumption. Prey consumption at underlined intensities $\left(\mu \mathrm{E} \mathrm{s}^{-1} \mathrm{~m}^{-2}\right)$ did not differ significantly $(\mathrm{p}<0.05)$

ANOVA: $F_{5,6}=60.48, \mathrm{p}<0.001$

\begin{tabular}{llllll}
$10^{-6}$ & $10^{-8}{ }_{\text {(dark) }}$ & $10^{-5}$ & $10^{-4}$ & $10^{-3}$ & $10^{-2}$ \\
\hline
\end{tabular}

fed during the day (Fig. 5a) exhibited the same response to light level as fish fed during the night (Fig. 5b), consuming more prey in the light $\left(10^{-3} \mu \mathrm{E} \mathrm{s}^{-1}\right.$ $\left.\mathrm{m}^{-2}\right)$ than in the dark $\left(F_{1,16}=232.31, \mathrm{p}<0.001\right.$; time $x$ light interaction: $F_{1,16}=1.35, \mathrm{p}=0.262$ ). Because night trials were conducted approximately 1 mo later than day trials, fish from night trials had grown and were significantly larger than day trial fish (night: $\bar{x}=$ $63.5 \mathrm{~mm}, \mathrm{SE}=0.8 ;$ day: $54.6,0.834 ; F_{1,96}=55.18, \mathrm{p}<$ 0.001 ). Fish length did not differ between light and dark during either day or night trials (light/dark: $F_{1,96}$ $=0.03, \mathrm{p}=0.863$; light/dark $\times$ day/night interaction: $F_{1,96}=0.39, \mathrm{p}=0.534$ ).

\section{DISCUSSION}

Both juvenile walleye pollock and sablefish are capable of nonvisual feeding in the darkness, but are much more efficient when there is adequate light for visually mediated foraging. The light threshold for visual feeding by juvenile walleye pollock, approximately $5 \times 10^{-7} \mu \mathrm{E} \mathrm{s}^{-1} \mathrm{~m}^{-2}$, is lower than those reported for other post-larval fishes (Hunter 1968, McMahon \& Holanov 1995) and approximately 2 orders of magnitude below the threshold for juvenile sablefish $(5 \times$ $10^{-5} \mu \mathrm{E} \mathrm{s}^{-1} \mathrm{~m}^{-2}$ ). This suggests that juvenile walleye pollock are able to use vision to feed at greater depths, where there is less light, than are juvenile sablefish. These thresholds also have the potential to influence temporal patterns of feeding in these species. For example, the intensity of starlight at sea surface on a clear night is approximately $7 \times 10^{-6} \mu \mathrm{E} \mathrm{s}^{-1} \mathrm{~m}^{-2}$ (U.S. Department of the Navy 1952). At this illumination, juvenile walleye pollock will be above their threshold for visual feeding and should be capable of visually detecting and capturing, at close range, prey with behavior and escape capabilites comparable to those of adult Artemia sp. Assuming a light extinction coefficient $(k)$ of 0.15 , which represents relatively high water clarity for the Gulf of Alaska (Jeff Napp, Alaska Fisheries Science Center, NMFS, pers. comm.), and a relationship in which light $\mathrm{at}_{\text {depth }}=$ light $_{\text {at }}$ surface $\mathrm{e}^{-k \text { (depth)}}$, then juvenile walleye pollock should be able to engage 
in some degree of visual foraging down to a depth of $18 \mathrm{~m}$. Under a full moon, at an altitude of $45^{\circ}$, with $4.8 \times 10^{-3} \mu \mathrm{E} \mathrm{s}^{-1} \mathrm{~m}^{-2}$ at the sea surface, this depth may be extended down to as much as $61 \mathrm{~m}$. Naturally, water clarity and sea surface and meteorological conditions may all act to decrease these depth limits for visual foraging. As a result, the ability of juvenile walleye pollock to forage nocturnally probably varies on a night-by-night basis. With a visual threshold 2 orders of magnitude higher than that of walleye pollock, juvenile sablefish are likely precluded from visual feeding at night in the absence of moonlight. With a full moon, they may be able to feed to a depth of $30 \mathrm{~m}$, or approximately half the depth estimated for walleye pollock. In making these calculations, we have made many simplifying assumptions regarding the reflection, refraction and transmission of light at and below the waters surface. Furthermore, we utilized a single prey, Artemia sp., as a surrogate for the many prey, with differing behavior capabilities, upon which these fish normally feed. As a result, these visual feeding depth thresholds should be regarded as preliminary estimates, or hypotheses, which will require refinement and/or testing through additional laboratory and field study.

The potential bias associated with our use of Artemia $\mathrm{sp}$. as a surrogate for natural prey deserves further discussion. Escape capabilities can vary considerably between zooplankter species (Drenner et al. 1978 , Drenner \& McComas 1980). Given adequate light, planktivorous fish are often capable of pursuing and capturing evasive prey such as calanoid copepods (Confer \& Blades 1975). However, with lower light and decreased detection distances (Vinyard \& O'Brien 1976, Howick \& O'Brien 1983), initial escape responses may remove prey from the planktivores visual field, increasing the likelihood of prey escape. In contrast, Artemia sp. possess rather feeble predator avoidance and escape capabilities (authors' pers. obs.). Once detected by a predator, Artemia sp. are probably less likely to escape than more elusive prey, particularly in low light or darkness, where escape responses by wild prey would be most effective (Vinyard \& O'Brien 1976). Thus, it is likely that threshold light intensities and depths for visually mediated feeding are prey species or prey type specific, and our estimates, while representative of some prey, likely overestimate the capabilities of juvenile walleye pollock and sablefish with respect to others.

The fish eye is differentially sensitive to various spectra (Douglas \& Hawryshyn 1990) and the spectral composition of ambient light varies temporally, with meteorological conditions, with depth, and as a function of the dissolved and suspended materials (McFarland 1986). Since we did not know the spectral sensitiv- ities of either the walleye pollock eye or the sablefish eye, we had to make a decision regarding the spectral conditions under which both fish were to be tested. In our threshold experiments, we utilized green light (555 nm) for illuminations of $10^{-3} \mu \mathrm{E} \mathrm{s}^{-1} \mathrm{~m}^{-2}$ and below, since this is the most ubiquitous wavelength in coastal marine waters, both day and night (McFarland 1986), and therefore represented the best compromise spectral environment under which visual capabilities could be assessed. For higher illuminations we had to provide supplemental incandescent lighting, which resulted in a shifting of spectral composition. Without knowing the precise spectral sensitivity of the walleye pollock or sablefish eye, it is impossible to know how this shifting of wavelengths might have influenced the shape of the curves for illumination versus feeding or behavioral response. However, the dynamic portions of these curves occurred at illuminations well below those where light changed from green to multispectral. As a result, we consider it unlikely that this change in spectral composition at these higher illuminations significantly biased our findings.

With the sun at its zenith, underwater light reaching the eye is at its maximum when looking straight up $\left(0^{\circ}\right)$. Light decreases gradually at first, as the eye follows a downward arc, and then more rapidly, due to refraction, from 40 to $50^{\circ}$. Following this rapid change, the decrease again becomes gradual, with light reaching its lowest level when the eye is looking straight downward $\left(180^{\circ}\right)$ (Jerlov 1970). This radial distribution of light in the ocean allows predators to see prey silhouetted against the bright sky above them, while the prey has greater difficulty differentiating the predator from the darkness below (Munz \& McFarland 1973). In our IR observation tanks, light decreased in an arc from vertically overhead to the horizontal, but increased again from the horizontal to vertically below. Therefore, at low illuminations, juvenile walleye pollock and sablefish were probably able to visually detect prey in 2 'windows', one below them and one above. This visual environment probably closely mimics the shallow sandy bottomed habitats where we routinely collect juvenile walleye pollock (Ryer \& Olla 1992, 1997, 1998), but differs from the deeper coastal and oceanic waters where sablefish and older juvenile and adult walleye pollock reside. It is likely that fish consumed more prey than they would have had the visual field below them been darker. Since light conditions in the field can vary greatly, this further emphasizes that the value of laboratory studies such as ours lies not in making detailed predictions regarding fish performance in the field, but in its usefulness for contrasting the relative capabilities of species and generally indicating conditions when light may be expected to become a limiting factor. 
The importance of nonvisual feeding in the energy budget of juvenile walleye pollock is unclear. Our data suggest that juvenile walleye pollock are opportunistic foragers. While inadequate to confirm or reject the existence of subtle endogenous rhythms, our data does indicate that when fish are hungry, and food is present, juvenile walleye pollock feed on Artemia sp. day or night, light or dark. We must qualify this by acknowledging that in our day/night rhythm experiment, the juvenile walleye pollock used at night were larger averaging $63.5 \mathrm{~mm}$, than those used during the day, which averaged $54.6 \mathrm{~mm}$. Although this size difference might be considered minor, ontogenetic changes in visual capabilities and/or diel feeding behaviors could represent a confounding factor in the interpretation of these data. In any case, examination of stomach contents indicate that juvenile walleye pollock do forage nocturnally in the field. A combined acoustic and midwater trawl survey in the western Gulf of Alaska during September 1990 revealed that at dusk juvenile walleye pollock (53 to $107 \mathrm{~mm}$ TL) were migrating upward from near bottom to a depth of 10 to $40 \mathrm{~m}$, where individuals dispersed and fed through the night upon larvaceans, euphausiids and copepods (Brodeur \& Wilson 1996, Merati \& Brodeur 1996). At dawn, juveniles returned to near bottom and decreased their feeding. On the dates these samples were taken, September 8 to 22,1990 , lunar phase varied from nearly full to new, with heavy cloud cover. No light measurements were made, but it is probable that, on some of the nights in question, juvenile walleye pollock were foraging at or below their visual thresholds.

Without vision, the distance at which fish can detect prey is greatly decreased and encounters with prey are less frequent (Vinyard \& O'Brien 1976). As a result, high prey densities are probably necessary for fish such as juvenile walleye pollock and sablefish to forage effectively in darkness. The importance of prey density in determining forager success is well established (Holling 1966, Werner \& Hall 1974), and, below a certain prey density threshold, fish may forage sporadically or cease foraging altogether. In laboratory experiments, Connaughton et al. (1994) found that larval weakfish Cynoscion regalis were only able to feed in the dark at very high rotifer Brachionus plicatilis densities $\left(10000^{-1}\right)$. Similarly, in laboratory experiments with underyearling bream Abramis brama in the dark, foraging became intermittent and nonforaging activities increased as Daphnia magna density decreased below a threshold level $\left(5.6 \mathrm{l}^{-1}\right)$, whereas in the light bream continued foraging actively at even the lowest prey densities examined $\left(0.56 \mathrm{l}^{-1}\right.$, Townsend \& Risebrow 1982), It is likely that the walleye pollock's prey density threshold for the onset of foraging is also higher in the darkness than in the light. Thus, when prey are abundant or aggregated into discrete depth strata that can be located and exploited during vertical migration, we would expect that juvenile walleye pollock would forage nocturnally, particularly if predation risk or zooplankton dispersal constrains their foraging during the day. In contrast, when prey are scarce or remain dispersed, juvenile walleye pollock should consume the bulk of their food diurnally, when vision will increase encounters with prey.

Compared to walleye pollock, little is known about the ecology of juvenile sablefish. With a visual foraging threshold 2 orders of magnitude higher than juvenile walleye pollock, juvenile sablefish do not appear well adapted to visually mediated feeding in low illumination environments. This is consistent with the observation that juvenile sablefish are present during the night in the neuston (Shenker 1988, present study), where ambient illumination would be greatest. During daylight hours, the absence of juvenile sablefish from neuston tows has been generally attributed to gear avoidance (Shenker 1988, Doyle 1992). However, in laboratory experiments, Sogard \& Olla (1998) found a tendency for juvenile sablefish to move downward in the water column during the day. Preliminary data on sablefish feeding periodicity indicate that they are primarily diurnal feeders (Sogard unpubl.). If they do make daily vertical migrations, and visual feeding is the primary factor controlling these movements, our data on their visual capabilities would suggest that these vertical movements would likely be modest compared to those of juvenile walleye pollock.

In the absence of vision, lateral line sensory input is the probable means by which fish orient to objects (Dijkgraaf 1962, Schwartz \& Hasler 1966). Pressure waves produced by swimming crustaceans stimulate the lateral line receptors in Pagothenia borchgrevinski (Montgomery \& MacDonald 1987). Furthermore, additional studies demonstrate that lateral line sensory input allows several fish species to detect and attack prey in the dark (Janssen 1990, 1997, Janssen et al. 1995) and enables temporarily blinded saithe Pollachius virens to school with conspecifics (Pitcher et al. 1976, Partridge \& Pitcher 1980). Although we cannot rule out the potential role of olfactory cues, we consider it probable that juvenile walleye pollock and sablefish detected prey in the dark using their lateral line systems. In both species, detection appeared to occur at distances less than $10 \mathrm{~mm}$, as has been reported for other species, e.g. common bream Abramis brama (Townsend \& Risebrow 1982) and alewife (Janssen et al. 1995), which rely upon their lateral line system for locating prey in the dark.

Feeding under low light or in darkness may necessitate behavior which differs from that exhibited when light is not limiting. Many species of fish decrease their 
activity or swimming at night (Helfman 1979), possibly to lower energetic costs (Neilson \& Perry 1990, Sogard \& Olla 1996) or to facilitate maintenance of congregations when there is insufficient light for visually mediated shoaling (Emery 1973, Ryer \& Olla 1998). For those species which feed at night or at great depth, decreased swimming speed may also aid in the visual detection of prey in low light or facilitate lateral line detection of prey hydromechanical signatures. In the present study, both juvenile walleye pollock and sablefish swam more slowly while foraging in darkness than at high light levels. Interestingly, at $1.90 \times 10^{-7} \mu \mathrm{E} \mathrm{s}^{-1}$ $\mathrm{m}^{-2}$, a light level below their visual foraging threshold, juvenile walleye pollock detected and behaviorally responded to light by swimming faster. The ecological significance of this response is unclear, but may represent a phototaxis or conspecific search behavior. In any case, at $1.05 \times 10^{-6} \mu \mathrm{E} \mathrm{s}^{-1} \mathrm{~m}^{-2}$, just above their visual foraging threshold, fish slowed their swimming to speeds comparable to those in the darkness, probably to maximize the probability of visually detecting prey. With subsequent increases in illumination, fish increased their swimming speed. Unfortunately, our measurement of swimming speed failed to capture the changes in the pattern of prey search which we observed. At low speeds, juvenile walleye pollock appeared to employ a pattern of prey search characterized by several tail beats, to initiate forward movement, and then coasting for a distance of 10 or $20 \mathrm{~cm}$, as has been described for the ruffe Gymnocephalus cernuus (Janssen 1997). Another succession of tail beats was either initiated during the coasting phase, or the fish came to a stop and paused before moving again. Prey appear to have been detected during coasts and pauses. At higher illuminations the tail beating became more continuous, the coasts and pauses less frequent, and prey appeared to be more commonly detected during active tail beating. Thus, it would appear that juvenile walleye pollock shifted from a thrust-glide to a cruising mode of search as prey became more visible, as has been described for juvenile alewife (Janssen et al. 1995). Unless resting on the tank bottom, juvenile sablefish engaged in continual cruising, probably because they lack a swimbladder and must swim to avoid sinking.

In conclusion, juvenile walleye pollock have a low light threshold for visually mediated foraging that is consistent with their vertical migratory behavior, keeping them in dimly lit habitats both day and night. Juvenile sablefish have a higher threshold, indicating that they would be less capable than walleye pollock to visually feed under low light conditions. This appears to be consistent with the scant data indicating that they reside at or near the waters surface throughout the diel cycle. Both species were capable of limited nonvisual foraging, but this capability is probably dependent upon high prey density.

Acknowledgements. We wish to thank Mara Spencer, Jim Burke, Mike Shaw, Michele Ottmar and Erick Sturm, Richard Titgen and Jasef Marshall for their painstaking care in counting and recounting thousands of brine shrimp and for the long hours spent analyzing videotapes. Special thanks go to Cindy Sweitzer for her assistance in preparing the manuscript

\section{LITERATURE CITED}

Bagarinao T, Hunter JR (1983) The visual feeding threshold and action spectrum of northern anchovy (Engraulis mordax) larvae. CALCOFI Rep XXIV:245-254

Bailey KM (1989) Interaction between the vertical distribution of juvenile walleye pollock Theragra chalcogramma in the eastern Bering Sea, and cannibalism. Mar Ecol Prog Ser 53:205-213

Baird TA, Ryer $\mathrm{CH}_{4}$ Olla BL (1991) Social enhancement of foraging on an ephemeral food source in juvenile walleye pollock, Theragra chalcogramma. Environ Biol Fishes 31: 307-311

Bergman E (1988) Foraging abilities and niche breadths of two percids, Perca fluviatilis and Gymnocephalus cernua, under different environmental conditions. J Anim Ecol 57 : $443-453$

Blaxter JHS (1964) Spectral sensitivity of the herring, Clupea harengus L. J Exp Biol 41:155-162

Blaxter JHS (1965) The effect of light intensity on the feeding ecology of herring. In: Bainbridge R, Evans GC, Rackham $O$ (eds) Light as an ecological factor. John Wiley \& Sons, Inc, New York, p 393-409

Brodeur RD, Wilson MT (1996) Mesoscale acoustic patterns of juvenile walleye pollock (Theragra chalcogramma) in the western Gulf of Alaska. Can J Fish Aquat Sci 53: $1951-1963$

Confer JL, Blades PI (1975) Omnivorous zooplankton and planktivorous fish. Limnol Oceanogr 20:571-579

Confer JL, Howick GL, Corzette MH, Kramer SL, Fitzgibbon S, Landesberg R (1978) Visual predation by planktivores. Oikos 31:27-37

Connaughton VP, Epifanio CE, Thomas R (1994) Effects of varying irradiance on feeding in larval weakfish (Cynoscion regalis). J Exp Mar Biol Ecol 180:151-163

Dabrowski KR, Jewson DH (1984) The influence of light environment on depth of visual feeding by larvae and fry of Coregonus pollan (Thompson) in Lough Neagh. J Fish Biol 25:173-181

Day RW, Quinn GP (1989) Comparisons of treatments after an analysis of variance in ecology. Ecol Monogr 59:433-463

Dijkgraaf S (1962) The functioning and significance of the lateral-line organs. Biol Rev 38:51-105

Douglas RH, Hawryshyn CW (1990) Behavioural studies of fish vision: an analysis of visual capabilities. In: Douglas RH, Djamgoz MBA (eds) The visual. system of fish. Chapman \& Hall, London, p 373-418

Doyle MJ (1992) Neustonic ichthyoplankton in the northern region of the California current ecosystem. CALCOFI Rep 33:141-161

Drenner RW, McComas SR (1980) The roles of zooplankter escape ability and fish size selectivity in the selective feeding and impact of planktivorous fish. In: Keerfoot WC (ed) Evolution and ecology of zooplankton communities. University Press of New England, Hanover, p 587-593 
Drenner RW, Strickler JR, O'Brien WJ (1978) Capture probability: the role of zooplankter escape in the selective feeding of planktivorous fish. $J$ Fish Res Board Can 35: $1370-1373$

Emery AR (1973) Preliminary comparisons of day and night habitats of freshwater fish in Ontario lakes. J Fish Res Board Can 30:761-774

Helfman GS (1979) Twilight activities of yellow perch, Perca flavescens. J Fish Res Board Can 36:173-179

Hicks C (1982) Fundamental concepts in the design of experiments. Holt Rinehart and Winston, New York

Higgs DM, Fuiman LA (1996) Light intensity and schooling behaviour in larval gulf menhaden. J Fish Biol 48:979--991

Holling CS (1966) The functional response of invertebrate predators to prey density. Entomol Soc Can Mem 48:1-86

Howick GL, O'Brien WJ (1983) Piscivorous feeding behavior of largemouth bass: an experimental analysis. Trans Am Fish Soc 112:508-516

Hunter JR (1968) Effects of light on schooling and feeding of jack mackerel, Trachurus symmetricus. J Fish Res Board Can 25:393-407

Huse I (1994) Feeding at different illumination levels in larvae of three manine teleost species: cod, Gadus morhua L. plaice, Pleuronectes platessa L., and turbot, Scophthalmus maximus (L.). Aquacult Fish Manage 25:687-695

Janssen $J(1990)$ Localization of substrate vibrations by the mottled sculpin (Cottus bairdi). Copeia 1990:349-355

Janssen J (1997) Comparison of response distance to prey via the lateral line in the ruffle and yellow perch. J Fish Biol 51:921-930

Janssen J, Jones W, Whang A, Oshel PE (1995) Use of the lateral line in particulate feeding in the dark by juvenile alewife (Alosa pseudoharengus). Can J Fish Aquat Sci 52 $358-363$

Jerlov NG (1970) Light: general introduction. In: Kinne O (ed) Marine ecology, Vol 1, Environmental factors, Part 1. John Wiley \& Sons, Inc, London, p 96-102

John KR (1964) Illumination, vision, and schooling of Astyanax mexicanus (Fillipi). J Fish Res Board Can 21: $1453-1473$

McFarland WN (1986) Light in the sea-correlations with behaviors of fishes and invertebrates. Am Zool 26:389-401

McMahon TE, Holanov SH (1995) Foraging success of largemouth bass at different light intensities: implications for time and depth of feeding. J Fish Biol 46:759-767

Merati N, Brodeur RD (1996) Feeding habits and daily ration of juvenile walleye pollock, Theragra chalcogramma, in the Western Gulf of Alaska. In: Brodeur RD, Livingston PA, Loughlin TR, Hollowed AB (eds) Ecology of juvenile walleye pollock, Theragra chalcogramma. NOAA Tech Rep 126, US Department of Commerce, Washington, DC, p $65-79$

Montgomery JC, MacDonald JA (1987) Sensory tuning of lateral line receptors in antarctic fish to the movements of planktonic prey. Science 235:195-235

Munz FW, McFarland WN (1973) The significance of spectral position in the rhodopsins of tropical marine fishes. Vision Res 13:1829-1874

Neilson JD, Perry RI (1990) Diel vertical migrations of marine

Editorial responsibility: Otto Kinne (Editor),

Oldendorf/Luhe, Germany fishes: an obligate or facultative process? In: Blaxter JHS, Southward AJ (eds) Advances in marine biology. Academic Press Ltd, London, p 115-168

Olla BL, Davis MW (1990) Behavioral responses of juvenile walleye pollock Theragra chalcogramma Pallas to light, thermoclines and food: possible role in vertical distribution. J Exp Mar Biol Ecol 135:59-68

Partridge BL, Pitcher TJ (1980) The sensory basis of fish schools: relative roles of lateral line and vision. J Comp Physiol A 135:315-325

Pitcher TJ, Turner JR (1986) Danger at dawn: experimental support for the twilight hypothesis in shoaling minnows J Fish Biol 29:59-70

Pitcher TJ, Partridge BL, Wardle CS (1976) A blind fish can school. Science 194:963-965

Ryer $\mathrm{CH}$, Olla BL (1992) Social mechanisms facilitating exploitation of spatially variable ephemeral food patches in a pelagic marine fish. Anim Behav 44:69-74

Ryer CH, Olla BL (1995) Influences of food distribution on fish foraging behaviour. Anim Behav 49:411-418

Ryer $\mathrm{CH}$, Olla BL (1997) Altered search speed and growth: social versus independent foraging in two pelagic juvenile fishes. Mar Ecol Prog Ser 153:273-281

Ryer CH, Olla BL (1998) Effect of light on juvenile walleye pollock shoaling and their interaction with predators. Mar Ecol Prog Ser 167:215-226

Schwartz E, Hasler AD (1966) Perception of surface waves by the blackstripe topminnow, Fundulus notatus. J Fish Res Board Can 23:1331-1352

Shenker JM (1988) Oceanographic associations of neustonic larval and juvenile fishes and Dungeness crab megalopae off Oregon. Fish Bull US 86:299-317

Shenker JM, Olla BL (1986) Laboratory feeding and growth of juvenile sablefish, Anoplopoma fimbria. Can J Fish Aquat Sci 43:930-937

Sogard SM, Olla BL (1993) Effects of light, thermoclines and predator presence on vertical distribution and behavioral interactions of juvenile walleye pollock, Theragra chalcogramma Pallas. J Exp Mar Biol Ecol 167:179-195

Sogard SM, Olla BL (1996) Diel patterns of behavior in juvenile walleye pollock, Theragra chalcogramma. Environ Biol Fishes 47:379-386

Sogard SM, Olla BL (1998) Behavior of juvenile sablefish Anoplopoma fimbria (Pallas), in a thermal gradient: balancing food and temperature requirements. J Exp Mar Biol Ecol 222:43-58

Sokal RR, Rohlf FJ (1969) Biometry. WH Freeman, San Francisco

Townsend CR, Risebrow AJ (1982) The influence of light level on the functional response of a zooplanktonivorous fish. Oecologia 53:293-295

US Department of the Navy (1952) Natural illumination charts. Bureau of Ships, Washington, DC

Vinyard GL, O'Brien WJ (1976) Effects of light and turbidity on the reactive distance of bluegill (Lepomis macrochirus). $J$ Fish Res Board Can 33:2845-2849

Werner EE, Hall DJ (1974) Optimal foraging and the size selection of prey by the bluegill sunfish (Lepomis macrochirus). Ecology 55:1042-1052

Submitted: July 3, 1998; Accepted: January 25, 1999

Proofs received from author(s): April 30, 1999 